\title{
Article
}

\section{Light Reflectance Characterization of Waste Glass Coating for Tiles}

\author{
Chaimae Mourou ${ }^{1}$, María Martín-Morales ${ }^{1}\left(\mathbb{D}\right.$, Montserrat Zamorano ${ }^{2}\left(\mathbb{D}\right.$ and Diego P. Ruiz ${ }^{3, *(D)}$ \\ 1 School of Building Engineering, University of Granada, 18071 Granada, Spain; \\ chaimaemourou@correo.ugr.es (C.M.); mariam@ugr.es (M.M.-M.) \\ 2 School of Civil Engineering, University of Granada, 18071 Granada, Spain; zamorano@ugr.es \\ 3 Faculty of Sciences, University of Granada, 18071 Granada, Spain \\ * Correspondence: druiz@ugr.es
}

check for updates

Citation: Mourou, C.;

Martín-Morales, M.; Zamorano, M.

Ruiz, D.P. Light Reflectance

Characterization of Waste Glass

Coating for Tiles. Appl. Sci. 2022, 12,

1537. https://doi.org/10.3390/

app12031537

Academic Editor: Asterios Bakolas

Received: 31 December 2021

Accepted: 29 January 2022

Published: 31 January 2022

Publisher's Note: MDPI stays neutral with regard to jurisdictional claims in published maps and institutional affiliations.

Copyright: (C) 2022 by the authors. Licensee MDPI, Basel, Switzerland. This article is an open access article distributed under the terms and conditions of the Creative Commons Attribution (CC BY) license (https:// creativecommons.org/licenses/by/ $4.0 /)$.

\begin{abstract}
Glass wastes that come from recycling plants do not often find a proper use, thus, they are discarded. In order to find future uses for these wastes, this paper explores the characterization of waste glasses (WGs) as a raw material through the assessment of their light reflectance if they were used for external coatings in building materials. To this aim, in this research, several claytile specimens were fabricated and coated with three different compositions of waste glass. For these specimens, three variables were analyzed to serve for this WG-based coating characterization: thickness of WG coating, temperature, and holding time of burning. The resulting WG-coated tiles were assessed in terms of the light spectral reflectance and whiteness index, with the help of a fiber optic spectrometer. Results show that the composition of WG had a very significant influence on the light spectral reflectance and the degree of whiteness, with holding time and WG thickness being the most influential depending on the WG type. The temperature of burning was also shown to be critical for the densification process. Finally, an interpretation of these results based on the WG chemical composition coatings obtained by XRF is discussed in this paper.
\end{abstract}

Keywords: waste glass; light reflectance; building material coatings; soda-lime-silica glass; lead-silica glass

\section{Introduction}

The remarkable increase of waste glass (WG) generation suggests the study and proposal of more sustainable techniques for waste management and recycling possibilities, which ultimately would benefit the ceramic industry. The adaptation of efficient WG management through the industrial production chain implies environmental gains related to landfilling avoidance, recovery of co-products, and an eco-friendly use of energy through the production process [1]. In accordance with the circular economy principles, an equilibrium should be settled between citizens, municipalities, and solid-waste recycling companies to create a closed-loop supply chain for the co-benefit of all stakeholders [2].

The non-biodegradable nature of glass makes it non-environmental friendly waste [3]; hence, creating new options for recycling WG will alleviate the pressure from both disposal procedures and raw-material extraction. According to the academic literature, promising results have been obtained from recycling WG in the production of eco-friendly ceramic materials regarding the physical, mechanical, and thermal properties [4-9]. However, the light-reflectance evaluation of coating materials containing WG was poorly discussed, especially in the visible and near-infrared radiation (NIR) spectrum [10,11], and this knowledge is relevant for indoor and outdoor environments in terms of human welfare and environmental comfort.

In general, WG was either integrated in substrate materials, such as bricks and tiles, or coating materials, such as glazes, engobes, and binders. For the production of new designs of glazes, the substitution procedure was totally applied in a combined kaolin and bottle WG for based materials of a new glaze [12], and partially, in the frits composition with a 
feasible amount of $8 \%$ mass as in the case of laminated WG used as a raw material [13]. Moreover, important gains were achieved regarding the cost of the new glazes with WG in their composition [14].

Among WG origins, soda-lime glass, also called soda-lime-silica glass (denoted as SLS), is the most abundant source of glass [15], which explains the growing interest in the research field for their potential use for radiation-shielding applications. The addition of several oxides, such as antimony (III) oxide $\left(\mathrm{Sb}_{2} \mathrm{O}_{3}\right)$, improves the radiation-shielding ability of soda-lime-silicate (SLS) WG network [16], and it decreases the X-ray transmission [17]. Moreover, the addition of both lanthanum oxide $\left(\mathrm{La}_{2} \mathrm{O}_{3}\right)$ and gadolinium oxide $\left(\mathrm{Gd}_{2} \mathrm{O}_{3}\right)$ has the ability to increase the linear attenuation coefficient (LAC) values and, hence, improve its gamma-rays-shielding characteristics [18]. Similar results were obtained with the addition of $\mathrm{MoO}_{3}$ [19]. Moreover, it is frequently found in WGs for their shielding applications and their optical properties the flint glass or lead silicate glass (denoted as LS), which contains a minimum of $24 \%$ (by weight) lead (II) oxide ( $\mathrm{PbO}$ ). A broad range of scientific studies used chelating treatments to recycle LS WG resulting from cathode ray tubes (CRT) [20,21], since the amounts of CRT wastes have increased around the world after gradually replacing it with liquid crystal displays (LCD) [22]. CRT glass could be considered as a substitute for non-plastic materials, in particular, ceramic frits obtained from mixtures of silicates and carbonates to produce ceramic glazes [23]. On the other hand, and in contrast to SLS WG, the lead silicate (LS) WG requires much more caution both in recycling and in the disposal measures, since it contains lead metal.

The objective of this work is to establish a first proof of concept related to the identification of the influence in both the specular light spectral reflectance and the degree of whiteness of the WG coated tile specimens, taking into account the type of WG materials and the manufacturing process characterized by the parameters of temperature of burning, thickness of WG coating, and time of burning.

In this regard, it is interesting to assess the light-reflectance properties of the WG coated tiles if they are planned to be used as coatings on tiles located in roofs, walls, or other applications in the construction sector. The characterization of solar-reflectance performance of WG coatings, especially in the near-infrared, was poorly discussed in the literature, and even less evidence on the use of waste glass as coatings on tiles. Therefore, a first proof of concept of this influence was performed by testing the relevance of variables, such as the WG-coated tile's composition, and other manufacturing features, such as the holding time or temperature of burning in the whiteness index or light spectral reflectance.

To achieve this goal, laboratory measurements were used to determine the light spectral reflectance and degree of whiteness of the specimens in the wavelength range of $350-1100 \mathrm{~nm}$. The overall process was divided into four main steps: characterization of raw materials, production of the specimens, firing stage, and, finally, several tests for the measurement of the degree of whiteness and the specular light reflectance were conducted. Therefore, this work aimed at the use of three different types of WG in the preparation of coating for clay tiles specimens: two types of SLS WGs with different compositions and an LS WG derived from CRT.

\section{Materials and Methods}

This research aimed to study the behavior of glazed clay surfaces made of WG in terms of their light-spectral-reflectance performance. In the experimental setup, several WG-coated tile specimens were manufactured by using three values of WG thickness $(0.5,0.75$, and $1 \mathrm{~mm})$, with different burning temperatures $\left(700,850\right.$, and $\left.1000{ }^{\circ} \mathrm{C}\right)$, using the laboratory kiln with different holding times $(20,40$, and $60 \mathrm{~min})$. In this section, the materials and their manufacturing based on the temperature of burning, thickness of WG coating, and time of burning are described. It is also described the experimental setup used to measure the specular light spectral reflectance and the degree of whiteness of the tile samples. 


\subsection{Origin of Materials}

In this work, three types of WG were used for coatings. The WGs were provided by the company "Camacho Recycling", and they were taken from the glass-collection plant located in Albacete, Spain. This company has developed glass-collection systems for all the different types of glass, regardless of the origin, composition, and quantities that can be generated on factories or homes. The preparation of the substrate (ceramic body) was carried out by using a clay powder provided by the local company "Ladrillos Suspiro del Moro S.L" in Granada, Spain, under the instructions and supervision of the research team. Both companies have a long history in the collection and recycling of waste glass, and the manufacturing of bricks or other construction materials.

\subsection{Preparation of the Flat-Tile Specimens}

According to the dosage provided by the company, 81 clay substrates of $3.2 \mathrm{~mm} \times$ $3.2 \mathrm{~mm} \times 1.5 \mathrm{~mm}$ were fabricated by mixing clay powder with $15 \mathrm{wt} . \%$ of water ("wt." stands for percentage of weight per unit volume). The production process is shown in Figure 1, and it can be summarized as follows:

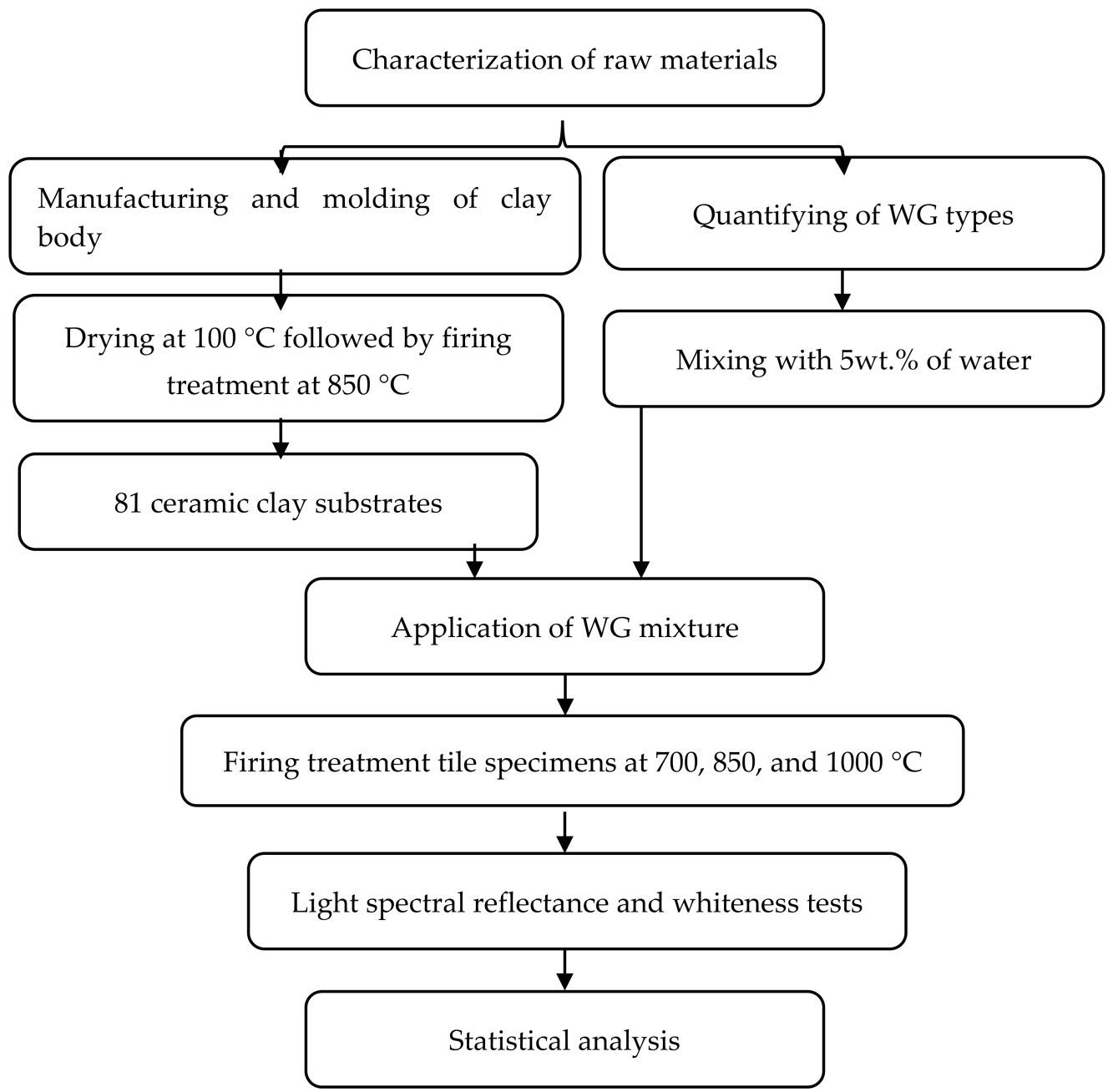

Figure 1. Flowchart of the research procedure.

Firstly, clay powder was processed and treated by a drying process until its weight was stabilized. Then the process was performed on a homogenous mixture of the resulted clay powder and water with the help of an electrical mixer. The molding of the substrates was achieved with the help of a mold (Figure 2) fabricated according to the dimensions required for the further tests' measurements. With the help of a compressive test machine, 
uniaxial pressing was applied on the mold to shape the clay body at $1000 \mathrm{MPa}$. This process was followed by a drying for $48 \mathrm{~h}$ under the temperature of $100{ }^{\circ} \mathrm{C}$ at the laboratory furnace, and then a firing treatment during $1 \mathrm{~h}$ under the temperature of $850{ }^{\circ} \mathrm{C}$ at the laboratory kiln. In this work, we opted for a double firing process; the biscuit state was obtained by drying the 81 clay substrates for $48 \mathrm{~h}$ at $100{ }^{\circ} \mathrm{C}$, using the laboratory furnace, followed by a firing treatment during $1 \mathrm{~h}$ at $850^{\circ} \mathrm{C}$, using the laboratory kiln.

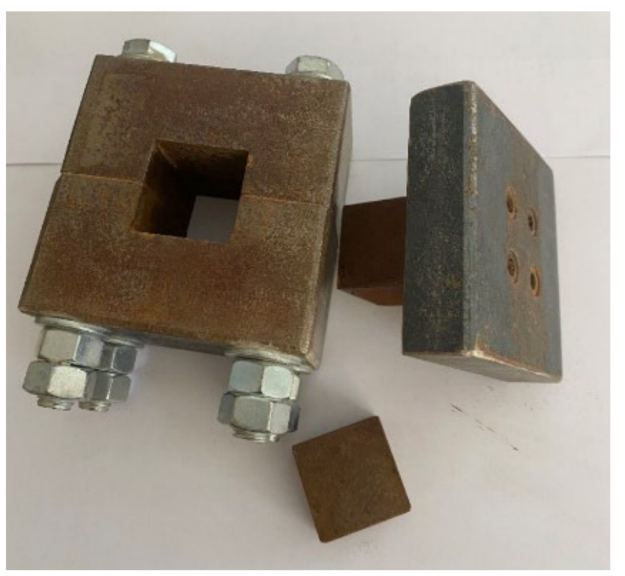

Figure 2. Mold used in the laboratory for the specimen shaping.

In a second step, the coating was added to the clay substrate. According to the varying parameters of the study, for the preparation of WG coatings, three quantities of each WG type representing the three values of thickness were mixed with $5 \mathrm{wt}$ \% of water (Table 1) in order to obtain a mixture that could be spread evenly enough to achieve the desired thicknesses. The next step was the manual addition of the mixture on the fired-clay body. Finally, the heat treatment was processed according to two variables: holding time and temperature, i.e., 20,40 , and $60 \mathrm{~min}$ for each of the temperatures of 700,850 , and $1000{ }^{\circ} \mathrm{C}$.

Table 1. Identification of WG specimens.

\begin{tabular}{cccc}
\hline Waste Glass (WG) Type & Particle Size (mm) & Identification & No. of Specimens \\
\hline 1st SLS WG & $(0,1)$ & WG1_Qx ${ }^{1} \_\mathrm{y}^{2}$ & 27 \\
2nd SLS WG & $(0-3)$ & WG2_Qx_y & 27 \\
LS WG & $(0-4)$ & WG3_Qx_y & 27 \\
\hline
\end{tabular}

${ }^{1}$ Thickness of WG coating $(\mathrm{Q} 1=0.5, \mathrm{Q} 2=0.75$ and Q3 $=1 \mathrm{~mm}) .{ }^{2}$ Time of burning: 20, 40, and $60 \mathrm{~min}$.

In summary, several samples of every coated tile were manufactured, and three samples for each one of the cases with different temperatures, holding time, and thickness were selected to be studied and used for the light spectral reflectance and whiteness measurements. In total, 27 samples of each WG type were chosen (Table 1).

\subsection{Chemical Characterization of Raw Materials and Clay Specimens Using XRF}

The characterization of the three WG types and the clay powder was conducted through the chemical composition obtained by X-ray fluorescence (XRF) analysis. This non-destructive test method is used to analyze the structure of the clay samples and reveal their chemical composition. In the XRF-based analysis, a primary X-ray beam was directed at a sample, and we measured the secondary X-ray emitted from a sample (called fluorescence) when it is excited by the primary X-ray source. Every element in a sample produces a set of unique characteristic fluorescent $X$-rays that allows us to determine the chemical composition of materials. The equipment used was a Philips MagiX 2400. The equipment was calibrated with the corresponding standard sample. The analysis of the majority elements was carried out by preparing a bead by mixing $0.3 \mathrm{~g}$ of sample and $5.5 \mathrm{~g}$ of Lithium Tetraborate. Quantification was carried out by using the quantitative analysis 
curve for silico-aluminous materials. When the concentration of the elements was low, i.e., they were present in trace form, the pressed tablet or pellet method was used.

\subsection{Surface Spectral Reflectance Measurement of WG Coated Tile Samples}

In this research, a spectrometer was used to perform the measurement of the specular light spectral reflectance of surfaces. For this type of reflectance measurements, the StellarNet miniature spectrometers family members are suitable, since they are a portable and compact fiber optic instruments for ultraviolet, visible (VIS), and near infrared (NIR) measurements offering CCD 2048 and PDA 512/1024 detectors with the required accuracy for the objectives of this research.

Specifically, the experimental setup was as follows (see Figure 3). For the measurements, a StellarNet BLUE-Wave Spectrometer of STN-BW-VIS type was used. This spectrometer is a fiber-optic-coupled instrument for measurements in the range of 350-1150 nm wavelength. It uses a 16-bit digitizer via high speed USB-2, and each unit contains a USB-2 interface with a snap shot memory to provide instantaneous spectral image from the highly sensitive CCD or Photo Diode Array detectors. The reflectance probe used was a STN-R600-8-VisNIR type for VIS and NIR (400-2200 nm wavelength) measurements. This probe was assembled in a reflectance probe holder for $90^{\circ}$ angle measurements and this strand fiber optic cable or probe assembly delivers input via standard SMA 905 fiber optic connector. The experimental setup also contains a light source STN-SL1 type, which is a 10,000 h Tungsten and Halogen lamp, 2800 Kelvin color temperature, 350-2500 nm (Figure 3). This spectrometer equipment was calibrated with NIST (National Institute of Standards and Technology) traceability.

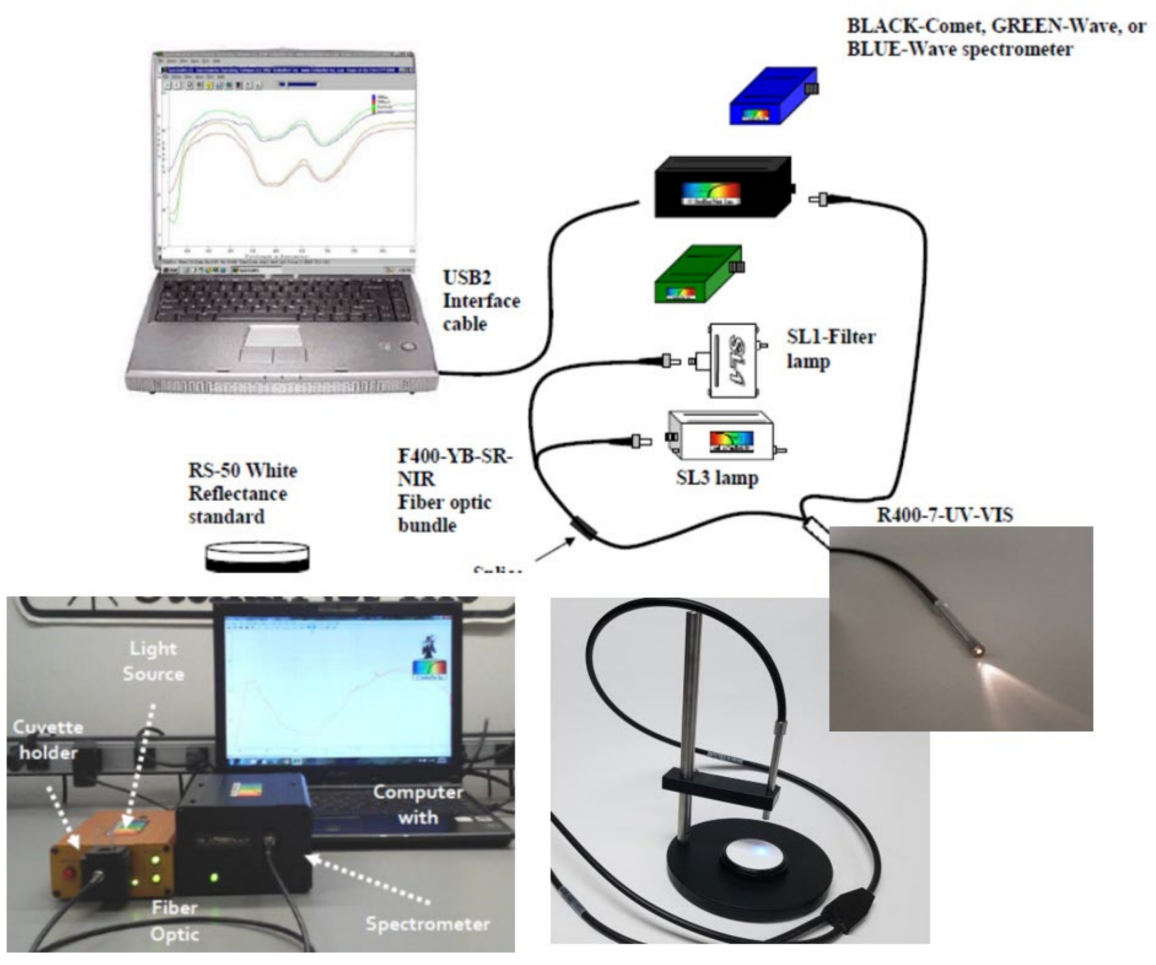

Figure 3. StellarNet BLUE-Wave Spectrometer STN-BW-VIS with the reflectance probe and probe holder for the light spectral reflectance measurements.

The equipment also contains the STN-RS50 reflectance standard, which is a $50 \mathrm{~mm}$ diameter white reflectance standard made of Halon. It is used to take reference measurements by using the R600-8 Reflectance Probe. The white standard will reflect $>97 \%$ of the light from 300 to $1700 \mathrm{~nm}$. Data were recorded by using the SpectraWiz software to accurately measure the light reflected intensity and perform other spectral calculations. 
Once the WG-coated tile specimen was placed in the sample holder in a dark lab room, the experimental reflectance data-collection procedure became as follows:

- $\quad$ Dark spectrum measurement: it records the background noise with the source turned off. Dark spectrum is subtracted from measurements.

- $\quad$ Reference spectrum measurement: it records the reference spectrum with the STNRS50 white reflectance standard.

- Sample spectrum measurement: it records the quotient between the sample reflectance spectrum and the reference spectrum of the RS50 standard.

For each reflectance measurement of the WG coated samples, the number of spectra to signal averaging was set. This option provides a smoothing effect, thus increasing the system signal-to-noise ratio by the square root of the number of scans being averaged. The rule is to set the averaging to the highest number tolerable when there is sufficient light signal, keeping the detector integration time short but out of saturation. In our measurements, the integration time was kept above $30 \mathrm{~ms}$ and at least 10 scans were averaged.

Since we manufactured three WG-coated tile samples with the same characteristics of holding time, temperature, and thickness, as stated in Section 2.2, the experimental data collection was performed for the 27 samples, and each measurement was repeated three times with each sample to ensure the quality of acquired data.

For all the samples, we measured the specular light spectral reflectance in the visible spectral range that extends from 400 to $700 \mathrm{~nm}$ and the NIR spectral range from 700 to $1100 \mathrm{~nm}$. We also computed the degree of whiteness or whiteness index denoted as $\mathrm{L}^{*}$ according the CIELAB D65 reference of the French-based international Commission on Illumination (CIE). This CIE whiteness index is a single number, which references the relative degree of near white materials under specific lighting conditions, and it correlates the visual ratings of whiteness for certain surfaces compared to the white-surface standard in the visible spectrum range. $L^{*}$ increases with whiteness, reaching for our applications the maximum value of 100 for the perfect white sample [24].

Finally, with the aim of gaining some insight of data, some measurements were processed through ANOVA analysis, using SPSS software. The statistical analysis focused on analyzing the existence of differences between the probability distributions for the different spectral reflectance measurements or whiteness index measurements of the WG coated tile samples. The normality of the data was checked by goodness-of-fit tests (P-P probability plots or the Kolmogorov-Smirnov test). In our cases, the data distributions were not normal, so the non-parametric Mann-Whitney $U$ test was used in all cases. The results were interpreted following the specific statistical analysis.

\section{Results}

In this section, we provide the results obtained for the WG-coated tile samples based on the effect of variables such as temperature of burning, thickness of WG coat, and time of burning in the specular light spectral reflectance and whiteness index, following the methodology described in the preceding section. We also give the experimental chemical characterization of materials of the tile samples.

\subsection{Chemical Characterization of Raw Materials}

WG particles used in this study were classified into three types, based on their origins, grain sizes, and chemical compositions (Table 2). The XRF chemical characterization of the glass shows that it contains $\mathrm{SiO}_{2}$; fluxing elements, such as $\mathrm{Na}_{2} \mathrm{O}, \mathrm{K}_{2} \mathrm{O}$, and $\mathrm{PbO}$; and stabilizing elements, such as $\mathrm{Al}_{2} \mathrm{O}_{3}, \mathrm{CaO}, \mathrm{BaO}$, and $\mathrm{MgO}$. The first type, denoted as WG1, is a hollow green glass that was collected from recycled bottles, and, according to its composition, it is an SLS type of glass. The second type (denoted as WG2) contains some flat glass, and it is an SLS-type glass, with the addition of a small quantity of stones and ceramic materials. The third type (denoted as WG3) is an LS glass mainly coming from CRT TV monitors. The clay powder was obtained by mixing two types of raw constituents, 
namely $40 \%$ grea and $60 \%$ lime. To eliminate the moisture, the samples were oven-dried at $100{ }^{\circ} \mathrm{C}$ for $24 \mathrm{~h}$ to constant mass.

Table 2. Average chemical composition in wt.\% of WG and clay obtained from FRX analysis. Please note that they are average values and do not necessarily add up to $100 \%$ for each element.

\begin{tabular}{cccccccccccc}
\hline & $\mathbf{S i O}_{\mathbf{2}}$ & $\mathbf{N a}_{\mathbf{2}} \mathbf{O}$ & $\mathbf{C a O}$ & $\mathbf{M g O}$ & $\mathbf{A l}_{\mathbf{2}} \mathbf{O}_{3}$ & $\mathbf{F e}_{\mathbf{2}} \mathbf{O}_{\mathbf{3}}$ & $\mathbf{K}_{\mathbf{2}} \mathbf{O}$ & $\mathrm{TiO}_{2}$ & $\mathbf{P}_{\mathbf{2}} \mathbf{O}_{5}$ & $\mathbf{B a O}$ & $\mathbf{P b O}$ \\
\hline Clay & 44.46 & 0.69 & 11.21 & 3.63 & 16.08 & 5.48 & 3.34 & 0.66 & 0.14 & - & - \\
$\mathrm{WG}^{1}$ & 73.2 & 11.4 & 10.8 & 1.35 & 2.03 & 0.31 & 0.88 & 0.066 & $<0.04$ & - & - \\
$\mathrm{WG}^{2}$ & 72 & 13 & 9 & 2 & 1.75 & $<0.1$ & 0.55 & - & - & - & \\
$\mathrm{WG3}^{3}$ & 52.5 & 6 & 3 & 1.75 & 2.25 & 0.15 & 7.5 & 0.075 & - & 2 & 20.5 \\
\hline
\end{tabular}

${ }^{1}$ SLS WG with a particle size between $(0$ and 1$) \mathrm{mm} .{ }^{2}$ SLS WG with a particle size between $(0$ and 3$) \mathrm{mm} .{ }^{3} \mathrm{LS}$ WG with a particle size between $(0$ and 4$) \mathrm{mm}$.

\subsection{Qualitative Visual Characterization of the WG Coated Specimens}

As a result of the firing treatment, none of the WG types reached the melting point up to the temperature of $700{ }^{\circ} \mathrm{C}$. At $850{ }^{\circ} \mathrm{C}$, WG1 and WG2 types created a dense coat that did not adhere to the substrate, whereas WG3 showed more densification; however, it did not cover the entire surface. At $1000{ }^{\circ} \mathrm{C}$, all types of WG reached the melting point, and a dense coat structure was formed. The tiles specimens fired at $1000{ }^{\circ} \mathrm{C}$ showed better properties in terms of material adhesion when compared to the 700 and $850{ }^{\circ} \mathrm{C}$ temperature cases. Hence, this temperature was set up, and according to the structure and aesthetical perspective, 27 specimens fired at $1000^{\circ} \mathrm{C}$ (Figure $4 \mathrm{a}-\mathrm{c}$ ) were selected for further tests. All the samples had a homogeneous visual appearance to ensure the reproducibility of data.

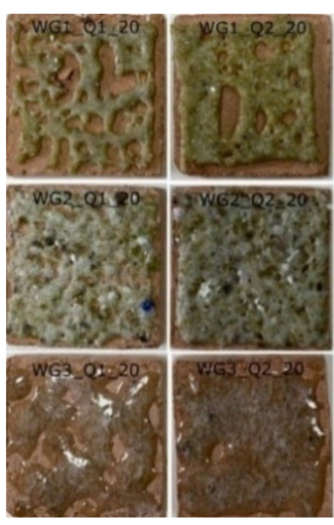

(a)
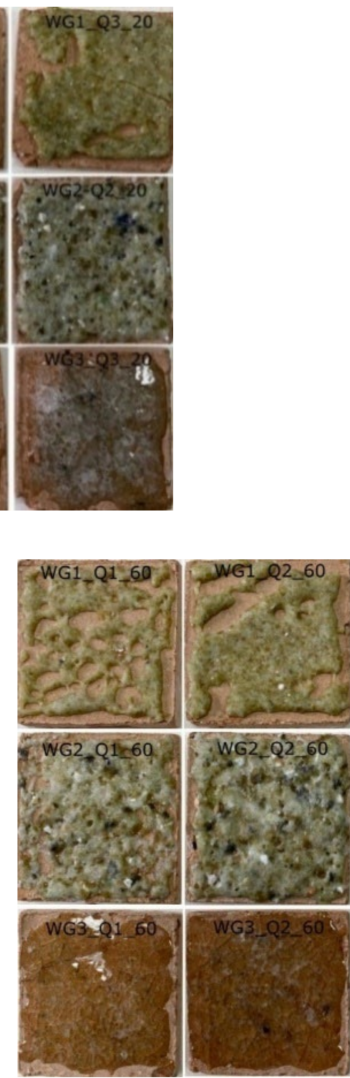

(c)

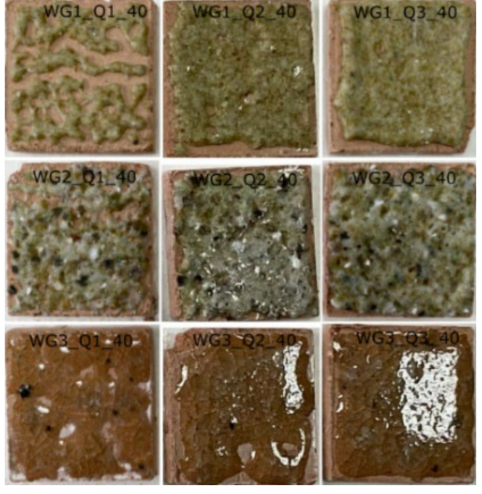

(b)
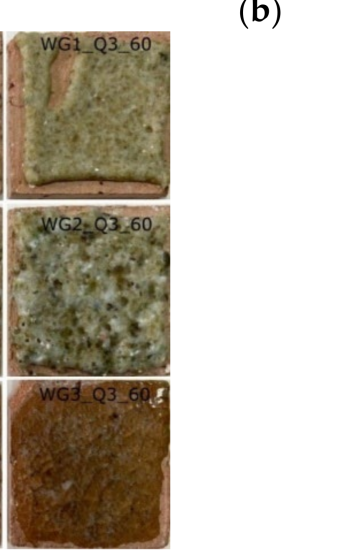
The coating structure of the three types of WG was different. According to Figure $4 \mathrm{a}$, WG1 presented a weak transition zone characterized by some cracking, and an unevenly distribution of melted WG due to particle shrinkage for small quantity of WG that improved with the increase of WG quantity. WG2 showed a porous surface and more roughness than the other types, and these qualities were notably reduced at a holding time of $60 \mathrm{~min}$ (Figure 4c).

WG1 and WG2 coatings had the appearance of an opaque surface lying on the substrate, but the WG3-coated samples had a glossy surface that is notably transparent; in fact, some breaks or rifts can be observed at the transition zone between the substrate and the coating. Moreover, WG3 coating contained air bubbles, and some pinholes occurred due to reactions of the oxides (Figure 4a). These effects decreased with the increase of the holding time (Figure 4c).

\subsection{Light Characterization of the WG-Coated Specimens}

Measurements of the whiteness index $L^{*}$ and light spectral reflectance measurements were taken for the 27 specimens described above. Table 3 shows the value of $L^{*}$ for the three WG-coated samples. In this table, WG1Q1 stands for the sample with a coating thickness of Q1 (Table 1) and so on. As can be observed in this table, the whiteness index ranged from 50.45 to 52.93 , with an average value of 51.78 , for WG1; it ranged from 49.24 to 55.23 , with an average value of 52.93, for WG2; and it ranged from 54.54 to 100 , with an average value of 84.49 , for WG3.

Table 3. Degree of whiteness $\left(\mathrm{L}^{*}\right)$ of the $27 \mathrm{WG}$-coated tile samples.

\begin{tabular}{|c|c|c|c|c|c|c|c|c|c|}
\hline \multirow{2}{*}{$\begin{array}{l}\text { Burning } \\
\text { Time }\end{array}$} & \multicolumn{9}{|c|}{$\mathbf{L}^{*}$} \\
\hline & WG1Q1 & WG1Q2 & WG1Q3 & WG2Q1 & WG2Q2 & WG2Q3 & WG3Q1 & WG3Q2 & WG3Q3 \\
\hline $20 \mathrm{~min}$ & 51.76 & 50.69 & 50.56 & 55.23 & 52.56 & 51.28 & 61.39 & 97.33 & 100 \\
\hline $40 \mathrm{~min}$ & 52.93 & 52.18 & 52.16 & 53.86 & 54.8 & 53.25 & 71.46 & 83.22 & 100 \\
\hline $60 \mathrm{~min}$ & 52.41 & 50.45 & 52.88 & 49.24 & 54.78 & 51.45 & 54.54 & 92.5 & 100 \\
\hline
\end{tabular}

An ANOVA analysis according to the methodology section was also performed on the data coming from Table 3, and all the results can be found in Appendix A. The statistical results coming from the nonparametric Mann-Whitney U test showed the following:

- In general, the variables "holding time of burning" and "thickness of WG coating" had no significant influence on the whiteness index.

- For the type of WG, the results showed no significant difference between the WG1 and WG2 types, in contrast to the WG3, which had a significant influence. In other words, the results show that there was no significant difference between the mean values of the whiteness index for the WG1- and WG2-coated types, and only the degree of whiteness of the WG3 type was significantly influenced at a $p<0.05$ level.

- The WG3 samples registered the highest values of the whiteness index.

Regarding the relative light spectral reflectance measurements, Figures 5-7 show the different light spectra reflectance obtained for the three WG-coated types of samples.

In this case, the influence of the holding time of burning and the WG-coated types on the spectral reflectance measurements was checked, since, from the manufacturing point of view, it is very interesting to know if there is an influence of the holding time on the spectral reflectance properties. Each figure represents the relative specular spectral reflectance of the WG1-, WG2-, and WG3-coated samples (according to Table 2) with different holding burning times. For example, WG1T20 stands for the WG1-coated sample measurements with a holding time of burning of $20 \mathrm{~min}$, and WG2T40 stands for the WG2-coated sample with a holding time of burning of $40 \mathrm{~min}$, and so on. Figure 5 shows the spectral reflectance data obtained for the 20 min burning time, Figure 6 for the 40 min burning time, and Figure 7 for the 60 min burning time. 


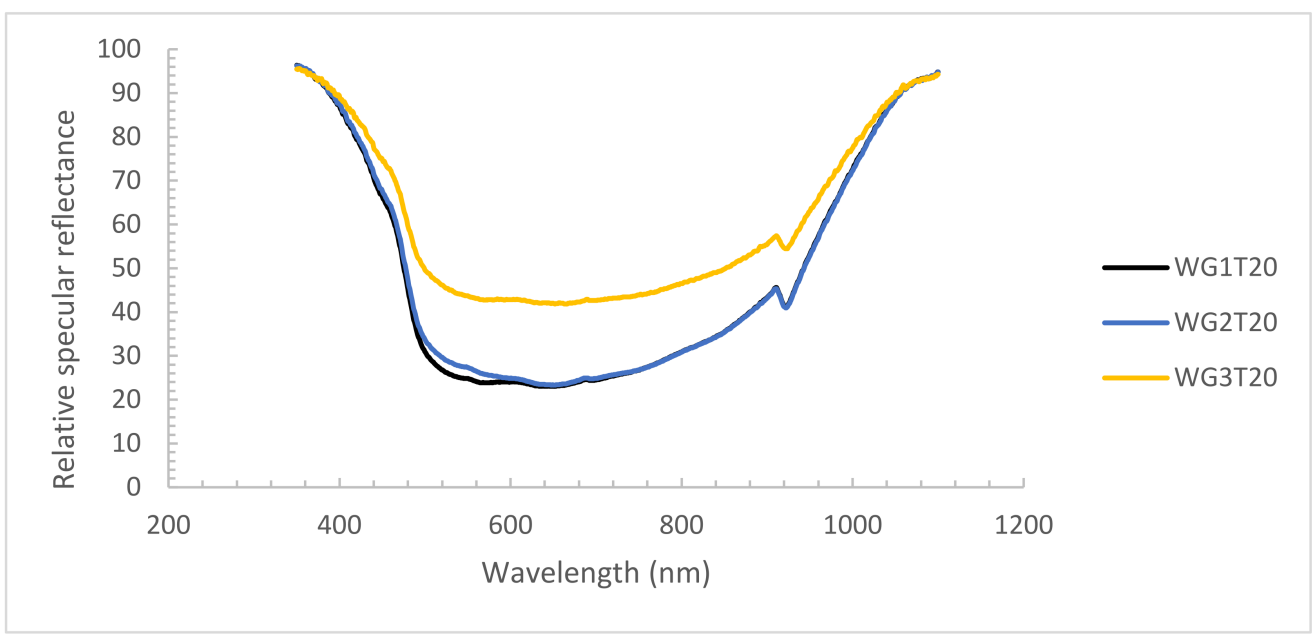

Figure 5. Specular light reflectance of the first set of specimens fired at $1000{ }^{\circ} \mathrm{C}$ during $20 \mathrm{~min}$.

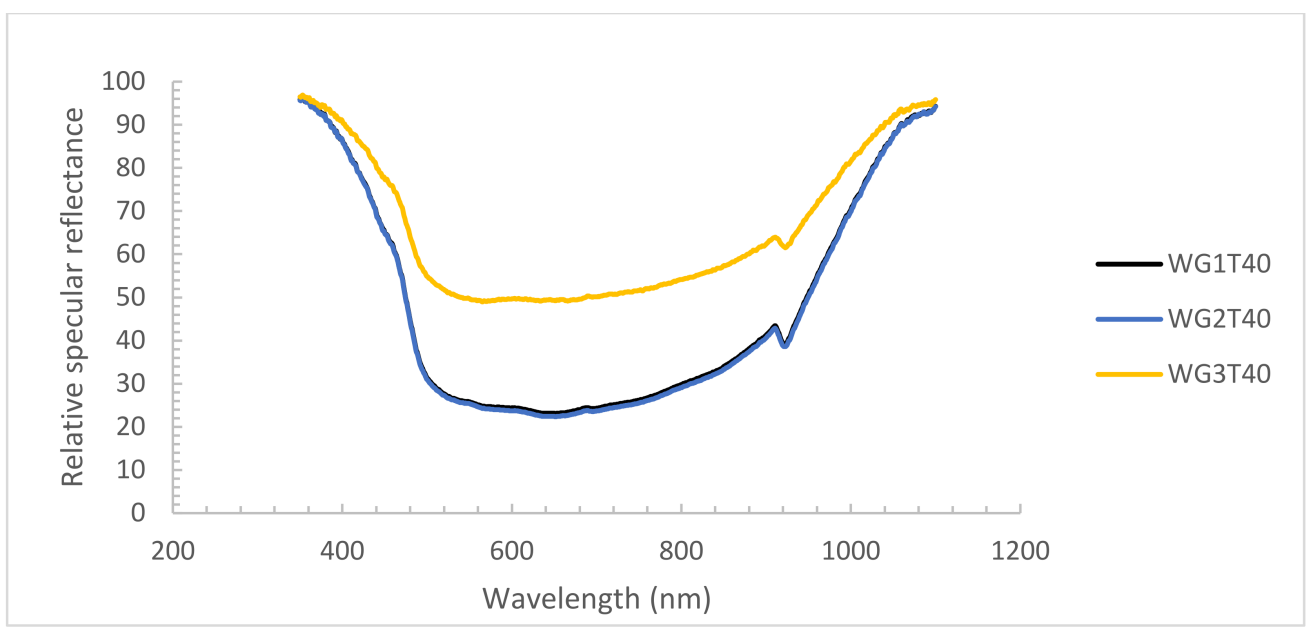

Figure 6. Specular light reflectance of the first set of specimens fired at $1000{ }^{\circ} \mathrm{C}$ during $40 \mathrm{~min}$.

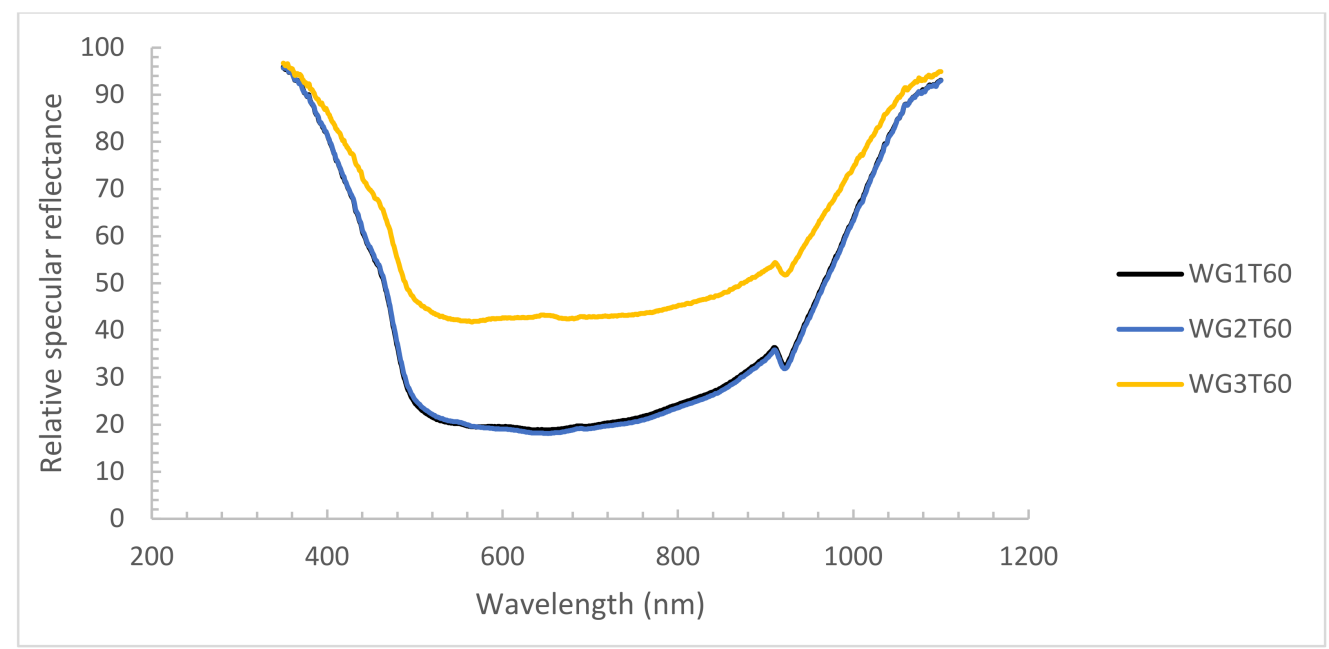

Figure 7. Specular light reflectance of the first set of specimens fired at $1000{ }^{\circ} \mathrm{C}$ during $60 \mathrm{~min}$.

As it can be observed from these figures, all types of WG-coated tiles reached a minimum light reflectance in the range of 500-800 nm, which tends to increase through the rest of the visual range and then increases gradually in the NIR range. The region in the 
range of 500-800 $\mathrm{nm}$, which roughly corresponds to the visible range (yellow, orange, and red colors), is the one showing almost constant and minimum values of the relative light reflectance. Therefore, these values are the most interesting ones to look for differences between the behavior of the samples on the global light reflectance, and they were chosen to perform a series of ANOVA tests, whose results are shown in Appendix B. In this case, the aim was to determine if the spectral data are really influenced by the WG type of glass coating or the holding times of burning.

From the nonparametric Mann-Whitney $U$ tests for the specular light spectral reflectance in terms of the WG type of glass coating and time of burning shown in Appendix B, the following can be concluded:

- There was a significant difference between all the types of WG coatings (WG1, WG2, and WG3) regardless of the holding time $(p<0.001)$.

- There was a significant difference between the holding burning times "20 and 60 min" and "40 and 60 min" of WG1 with $p<0.001$.

- There was no significant difference between the holding times "20 and 40 min" of WG1 with $p>0.01$.

- There was a significant difference between all the holding times of WG2 and WG3 with $p<0.001$.

- The WG3 type had the higher mean values, showing a greater reflection capacity compared to the other types.

In summary, this proof of concept about the spectral reflectance values of the WG coating showed that the light spectral reflectance behavior is highly influenced in the spectrum range that extends from 400 to $800 \mathrm{~nm}$ for the composition of the three types of glass used in the WG coatings. The holding time of burning also had some influence, but it was much smaller in general, except in the WG1 type between the 20 and 40 min burning times, wherein no difference was reported.

\section{Discussion}

The WG coatings tested in this research showed different behaviors during the sintering process. In this regard, the chemical and qualitative visual characterizations of the WG-coated specimens showed clear distinguishing features, and, consequently, it was expected that they would exhibit different values for the whiteness index and the light spectral reflectance. This consideration was checked by a set of experiments, and, thus, it was studied if a relevant different behavior for the WG-coated tiles in terms of both manufacturing feasibility and reflected radiant energy properties would be observed, taking into account their different WG composition and thickness of the coating, as well as other external manufacturing features, such as the holding times or temperatures of burning.

Focusing on the manufacturing process it was interesting to study two variables: holding time and temperature of burning. In our research, we used the holding times of 20, 40 , and $60 \mathrm{~min}$ for each of the burning temperatures of 700,850 , and $100{ }^{\circ} \mathrm{C}$. The three different types of WG used in this study showed different visual and physical structures after the firing treatment, with a better densification occurring at $1000{ }^{\circ} \mathrm{C}$ with respect to the other tested temperatures. Hence, this temperature was finally selected to build the WG-coated tiles for the next steps of the experiments.

Once this temperature was chosen and the WG coated tiles were manufactured, the degree of whiteness or whiteness index was measured using an experimental setup based on light spectrometry. The composition of WG (that defines the type) in this study, had a significant influence on the whiteness index $\left(\mathrm{L}^{*}\right)$ of the specimens. WG3 specimens had the highest mean value of $L^{*}(84.5)$ compared to the other types. This can be interpreted as that the small percentages of iron oxide increase the whiteness of the specimens, in accordance to other applications considered in [25] where the whiteness indicator of an engobe containing WG was influenced by the ratio of kaolin, alumina and zirconium. However, in contrast to the WG type or composition, in most cases, the holding time for the 
firing treatment and the thickness of the WG coating had a small influence on $\mathrm{L}^{*}$, especially for SLS WG specimens.

The third set of experiments considered the two most relevant variables (WG type and holding time) for checking for differences in the specular light spectral reflectance. In terms of light-reflectance measurements, it was measured the relative reflectance in the visible range from 350 to $700 \mathrm{~nm}$ and the NIR region from 700 to $1100 \mathrm{~nm}$. In this case, a set of WG1, WG2 and WG3 tiles obtained using three burning times of 20, 40 and $60 \mathrm{~min}$ respectively, were considered for testing if there are differences in the spectral reflectance.

From the obtained results, the composition of WG (that defines the type) in this study had again a relevant and significant influence on the light spectral reflectance of the specimens. Holding times had influence mainly in the reflectance properties for the WG2 and WG3 types, generally decreasing the values of reflectance but with a weak influence compared to the strong dependence with the WG type. For all the WG-coated tiles, WG3 had greater values of reflectance with respect to WG1 and WG2. This can be explained from its chemical composition, where the existence of substances with high refractive indexes such as $\mathrm{Al}_{2} \mathrm{O}_{3}$ and $\mathrm{TiO}_{2}$ enhances the light reflectance of specimens. In fact, this effect was also reported in other applications where the use of WG in the production of engobes and glazes compositions increased the refractive indexes [10,11]. According to the visual characterization, the glossy transparent structure of WG3 enhanced the light reflectance (Figure 4), based on the LS composition which has a high refractive index, and less internal friction with respect to SL glass [26].

In summary, these results are interpreted based on the chemical composition and the manufacturing process itself. With the increase of waste glass quantity, the degree of whiteness of lead silicate waste glass (LS WG) registered the highest values with respect to soda lime silicate glass (SLS WG). For the relative light reflectance, the lead silicate glass showed better performance with respect to the soda lime silicate glass due to its chemical composition. The difference of the light reflectance performance of the specimens could be explained by the percentage of crystalline phase developed through the sintering process of each type of WG, which makes the degree of whiteness results in agreement with the light reflectance measurements.

\section{Conclusions}

This research paper presented a preliminary study on using waste glass as a coating on tiles in terms of light reflectance. An optical characterization in terms of light-reflectance properties of the WG-coated tiles is provided by testing the relevance of variables, such as the WG-coated tile composition and other manufacturing features, such as the holding time or temperature of burning in the whiteness index or light spectral reflectance.

From a set of experiments based on raw WG coming from recycling plants, it was shown that the chemical composition and quantity of waste glass, as well as the temperature and holding time, had a significant influence on the light spectral reflectance of the specimens. The same results were found for the degree of whiteness, except from the holding burning time variable that had a minor impact. In general, the LS glass mainly coming from CRT TV monitors (WG3) had the highest mean value of the whiteness index and the higher light reflectance compared to the ones built with an SLS type of glass (WG1 and WG2). The holding time for the firing treatment and the thickness of WG coatings had a smaller influence on the whiteness index, especially weaker for the SLS WG specimens. Holding times also had an influence mainly in the reflectance properties for the LS-glass-coating type, generally decreasing the values of reflectance as the burning time increases.

Some potential benefits can be derived from this study to be considered for the use of SLS and LS waste glass in the production of coatings for clay tile specimens. The production of glazes as glass-ceramics is a result of a controlled crystallization process to fulfill the requirements of a prescribed design. Previous studies investigated the use of WG for the replacement of raw materials used in the production of glazes, and this replacement yielded promising results reducing energy consumption [12-14]. This is confirmed in this research, 
where a total replacement is carried out through the production of a WG coating material adopting sustainable routes as far as possible, ensuring a consistent seal and compatibility of the substrate and the coating if they were used in the construction sector. Moreover, it was shown that this use of WGs as coating affects the whiteness and the light reflectance performance of tiles, and so it becomes relevant the assessment of their potential impact in the outdoor or indoor environment in buildings, as well as cities. Depending on the specific outdoor environment, one or other coating types would be preferable. For example, if the application was aimed for cool roofs to reflect more sunlight and absorb less solar energy, it would be more suitable to use LS WG-coated tiles with one hour of holding times. Thus, the results obtained could be applied for the cool roof strategy as a main application that will provide, at the greatest extent, waste recovery and energy efficiency in buildings. More potential applications, such as their use in walls and pavements, will be further evaluated in future research.

Author Contributions: C.M. and M.M.-M., conceptualization, performed the experiments, writing the manuscript, formal analysis, and carried out the post-processing; M.Z. and D.P.R., conceptualization, writing the manuscript, project administration, funding acquisition, and supervising the manuscript. All authors have read and agreed to the published version of the manuscript.

Funding: This research was funded by the State Research Agency (AEI) of Spain and European Regional Development Funds (ERDF) under project PID2019-108761RB-I00.

Institutional Review Board Statement: Not applicable.

Informed Consent Statement: Not applicable.

Data Availability Statement: Data are available on request.

Acknowledgments: The authors wish to thank "Camacho Recycling" company for providing the samples used for this research.

Conflicts of Interest: The authors declare no conflict of interest.

\section{Appendix A. Statistical Analysis for the Whiteness Index}

Table A1. ANOVA for the whiteness of the specimens.

\begin{tabular}{ccccccc}
\hline Factor & Model & Sum of Squares & df & Mean Square & F & Sig. \\
\hline WG type & Linear & 6201.564 & 2 & 3100.782 & 28.708 & 0.000 \\
holding & Linear & 15.205 & 2 & 7.603 & 0.021 & 0.979 \\
time & Linear & 729.768 & 2 & 364.884 & 1.086 & 0.354 \\
thickness & & & &
\end{tabular}

Table A2. Ranks table of Mann-Whitney U test for the whiteness, according to the holding time.

\begin{tabular}{|c|c|c|c|c|}
\hline \multicolumn{5}{|c|}{ Ranks } \\
\hline & Holding Time & $\mathbf{N}$ & Mean Rank & Sum of Ranks \\
\hline \multirow{9}{*}{ Whiteness } & Holding time of $20 \mathrm{~min}$ & 9 & 8.39 & 75.50 \\
\hline & Holding time of $40 \mathrm{~min}$ & 9 & 10.61 & 95.50 \\
\hline & Total & 18 & & \\
\hline & Holding time of $20 \mathrm{~min}$ & 9 & 9.83 & 88.50 \\
\hline & holding time of $60 \mathrm{~min}$ & 9 & 9.17 & 82.50 \\
\hline & Total & 18 & & \\
\hline & Holding time of $40 \mathrm{~min}$ & 9 & 10.61 & 95.50 \\
\hline & holding time of $60 \mathrm{~min}$ & 9 & 8.39 & 75.50 \\
\hline & Total & 18 & & \\
\hline
\end{tabular}


Table A3. Test statistics table of Mann-Whitney U test for the whiteness, according to the holding time.

\begin{tabular}{cccc}
\hline \multicolumn{5}{c}{ Test Statistics } & \\
\hline Whiteness & & \\
\hline & $\mathbf{2 0 ~} \mathbf{~ m i n}$ & $\mathbf{4 0 ~} \mathbf{~ i n}$ & $\mathbf{6 0} \mathbf{~ m i n}$ \\
\hline Mann-Whitney U & 30.500 & 37.500 & 30.500 \\
Wilcoxon W & 75.500 & 82.500 & 75.500 \\
Z & -0.883 & -0.265 & -0.883 \\
Asymp. Sig. (2-tailed) & 0.377 & 0.791 & 0.377 \\
Exact Sig. [2*(1-tailed Sig.)] & 0.387 & 0.796 & 0.387 \\
\hline
\end{tabular}

Table A4. Ranks table of Mann-Whitney U test for the whiteness according to the thickness.

\begin{tabular}{ccccc}
\hline \multicolumn{5}{c}{ Ranks } \\
\hline Thickness & N & Mean Rank & Sum of Ranks \\
\hline \multirow{5}{*}{ Whiteness } & Q1 & 9 & 8.89 & 80.00 \\
& Q2 & 9 & 10.11 & 91.00 \\
& Total & 18 & & \\
\cline { 2 - 5 } & Q1 & 9 & 9.67 & 87.00 \\
& Q3 & 9 & 9.33 & 84.00 \\
\cline { 2 - 5 } & Total & 18 & & 8.00 \\
& Q2 & 9 & 9.33 & 87.00 \\
\hline & Q3 & 9 & & \\
\hline
\end{tabular}

Table A5. Test statistics table of Mann-Whitney U test for the whiteness, according to the thickness.

\begin{tabular}{cccc}
\hline \multicolumn{4}{c}{ Test Statistics } \\
\\
\hline Whiteness & & \\
\hline & Q1 & Q2 & Q3 \\
\hline Mann-Whitney U & 35.000 & 39.000 & 39.000 \\
Wilcoxon W & 80.000 & 84.000 & 84.000 \\
Z & -0.486 & -0.133 & -0.133 \\
Asymp. Sig. (2-tailed) & 0.627 & 0.894 & 0.894 \\
Exact Sig. [2*(1-tailed Sig.)] & 0.666 & 0.931 & 0.931 \\
\hline
\end{tabular}

Table A6. Ranks table of Mann-Whitney U test for the whiteness, according to the WG type.

\begin{tabular}{ccccc}
\hline \multirow{4}{*}{ Ranks } & & \\
\hline \multirow{6}{*}{ Whiteness } & N & Mean Rank & Sum of Ranks \\
\hline & WG1 & 9 & 7.56 & 68.00 \\
& WG2 & 9 & 11.44 & 103.00 \\
& Total & 18 & & \\
\cline { 2 - 5 } & WG1 & 9 & 5.00 & 45.00 \\
& WG3 & 9 & 14.00 & \\
\cline { 2 - 5 } & Total & 18 & & 48.00 \\
& WG2 & 9 & 5.33 & 123.00 \\
& WG3 & 9 & 13.67 & \\
\hline
\end{tabular}


Table A7. Test statistics table of Mann-Whitney U test for the whiteness according to the WG type.

\begin{tabular}{cccc}
\hline \multicolumn{3}{c}{ Test Statistics } & \\
\hline Whiteness & & WG3 \\
\hline WG1 & WG2 & 3.000 \\
Mann-Whitney U & 23.000 & 0.000 & 48.000 \\
Wilcoxon W & 68.000 & 45.000 & -3.318 \\
Z & -1.545 & -3.584 & 0.001 \\
Asymp. Sig. (2-tailed) & 0.122 & 0.000 & 0.000 \\
\hline Exact Sig. [2*(1-tailed Sig.)] & 0.136 & 0.000 & \\
\hline
\end{tabular}

\section{Appendix B. Statistical Analysis for the Specular Solar Reflectance}

Table A8. ANOVA for the specular light reflectance of the specimens.

\begin{tabular}{ccccccc}
\hline Factor & Model & Sum of Squares & df & Mean Square & F & Sig. \\
\hline $\begin{array}{c}\text { WG type } \\
\text { holding } \\
\text { time }\end{array}$ & Linear & 4153.132 & 2 & 2076.566 & $22,159.150$ & 0.000 \\
\hline
\end{tabular}

The specular solar reflectance of all types of WG does not follow a normal distribution; hence, the Mann-Whitney U test was carried out. A significant difference was found between all types of WG during each holding time, as shown in Appendix B Tables A9-A14 with a $p<0.001$.

Table A9. Ranks table of the Mann-Whitney U test for specular solar reflectance, according to the holding time of $20 \mathrm{~min}$.

\begin{tabular}{ccccc}
\hline \multirow{5}{*}{ WG } & Ranks & & \\
\hline \multirow{5}{*}{ Reflectance } & N & Mean Rank & Sum of Ranks \\
& WG1T20 & 607 & 531.00 & 322.31450 \\
& WG2T20 & 607 & 684.00 & 415.19050 \\
& Total & 1214 & & \\
\cline { 2 - 5 } & WG1T20 & 607 & 304.00 & 184.52800 \\
& WG3T20 & 607 & 911.00 & 552.97700 \\
\cline { 2 - 5 } & Total & 1214 & & \\
\cline { 2 - 5 } & WG2T20 & 607 & 304.00 & \\
& WG3T20 & 607 & 911.00 & 552.97700 \\
\hline
\end{tabular}

Table A10. Test statistics table of the Mann-Whitney U test for specular solar reflectance, according to the holding time of $20 \mathrm{~min}$.

\begin{tabular}{cccc}
\hline \multicolumn{3}{c}{ Test Statistics } \\
\hline & Reflectance \\
\hline WG1T20_WG2T20 & WG1T20_WG3T20 & WG2T20_WG3T20 \\
\hline Mann-Whitney U & 137.786500 & 0.000 & 0.000 \\
\hline Wilcoxon W & 322.314500 & 184.528000 & 184.528000 \\
\hline Z & -7.605 & -30.170 & -30.168 \\
\hline Asymp. Sig. (2-tailed) & 0.000 & 0.000 & 0.000 \\
\hline
\end{tabular}


Table A11. Ranks table of the Mann-Whitney test for specular solar reflectance, according to the holding time of $40 \mathrm{~min}$.

\begin{tabular}{ccccc}
\hline & \multicolumn{4}{c}{ Ranks } \\
\hline WG & N & Mean Rank & Sum of Ranks \\
\hline \multirow{5}{*}{ Reflectance } & WG1T40 & 607 & 669.97 & 406.67300 \\
& WG2T40 & 607 & 545.03 & 330.83200 \\
& Total & 1214 & & \\
\cline { 2 - 5 } & WG1T40 & 607 & 304.00 & 184.52800 \\
& WG3T40 & 607 & 911.00 & 552.97700 \\
& Total & 1214 & & \\
\cline { 2 - 5 } & WG2T40 & 607 & 304.00 & 554.52800 \\
& WG3T40 & 607 & 911.00 & \\
\hline
\end{tabular}

Table A12. Test statistics table of the Mann-Whitney U test for specular solar reflectance according to the holding time of $40 \mathrm{~min}$.

\begin{tabular}{cccc}
\hline \multicolumn{3}{c}{ Test Statistics } \\
\hline & Reflectance \\
\hline & WG1T40_WG2T40 & WG1T40_WG3T40 & WG2T40_WG3T40 \\
\hline Mann-Whitney U & 146.304000 & 0.000 & 0.000 \\
\hline Wilcoxon W & 330.832000 & 184.528000 & 184.528000 \\
\hline Z & -6.210 & -30.169 & -30.168 \\
\hline Asymp. Sig. (2-tailed) & 0.000 & 0.000 & 0.000 \\
\hline
\end{tabular}

Table A13. Ranks table of Mann-Whitney U test for specular solar reflectance, according to the holding time of $60 \mathrm{~min}$.

\begin{tabular}{ccccc}
\hline & \multicolumn{4}{c}{ Ranks } \\
\hline \multirow{5}{*}{ Weflectance } & N & Mean Rank & Sum of Ranks \\
\hline & WG1T60 & 607 & 663.64 & 402.83250 \\
& WG2T60 & 607 & 551.36 & 334.67250 \\
& Total & 1214 & & \\
\cline { 2 - 5 } & WG1T60 & 607 & 304.00 & 184.52800 \\
& WG3T60 & 607 & 911.00 & 552.97700 \\
& Total & 1214 & & \\
\cline { 2 - 5 } & WG2T60 & 607 & 304.00 & 184.52800 \\
& WG3T60 & 607 & 911.00 & 552.97700 \\
& Total & 1214 & & \\
\hline
\end{tabular}

Table A14. Test statistics table of Mann-Whitney test for specular solar reflectance, according to the holding time of $60 \mathrm{~min}$.

\begin{tabular}{cccc}
\hline \multicolumn{3}{c}{ Test Statistics } \\
\hline & Reflectance \\
\hline WG1T60_WG2T60 & WG1T60_WG3T60 & WG2T60_WG3T60 \\
\hline Mann-Whitney U & 150.144500 & 0.000 & 0.000 \\
\hline Wilcoxon W & 334.672500 & 184.528000 & 184.528000 \\
\hline Z & -5.583 & -32.253 & -32.248 \\
\hline Asymp. Sig. (2-tailed) & 0.000 & 0.000 & 0.000 \\
\hline
\end{tabular}


Appendix B Tables A15-A20 show a significant difference between the holding times "20 and 60 min" and "40 and 60 min" of WG1 with $p<0.001$. While there was no significant difference between the holding times "20 and 40 min" of WG1 with $p=0.046$.

There was a significant difference between all the holding times of WG2 and WG3 with $p<0.001$.

Table A15. Ranks table of Mann-Whitney U test for specular solar reflectance of WG1 during the three holding times.

\begin{tabular}{ccccc}
\hline \multirow{4}{*}{ WG } & Ranks & & \\
\hline \multirow{5}{*}{ Reflectance } & N & Mean Rank & Sum of Ranks \\
\hline & WG1T20 & 607 & 587.45 & 356.58400 \\
& WG1T40 & 607 & 627.55 & 380.92100 \\
& Total & 1214 & & \\
\cline { 2 - 5 } & WG1T20 & 607 & 895.54 & 543.59200 \\
& WG1T60 & 607 & 319.46 & 193.91300 \\
\cline { 2 - 5 } & Total & 1214 & & 545.55300 \\
& WG1T40 & 607 & 898.77 & \\
& WG1T60 & 607 & 316.23 & \\
\hline
\end{tabular}

Table A16. Test statistics table of Mann-Whitney U test for specular solar reflectance of WG1 during the three holding times.

\begin{tabular}{cccc}
\hline \multicolumn{3}{c}{ Test Statistics } \\
\hline & Reflectance \\
\hline WG1T20_WG1T40 & WG1T20_WG1T60 & WG1T40_WG1T60 \\
\hline Mann-Whitney U & 172.056000 & 9385.000 & 7424.000 \\
\hline Wilcoxon W & 356.584000 & 193.913000 & 191.952000 \\
\hline Z & -1.993 & -28.636 & -28.955 \\
\hline Asymp. Sig. (2-tailed) & 0.046 & 0.000 & 0.000 \\
\hline
\end{tabular}

Table A17. Ranks table of Mann-Whitney U test for specular solar reflectance of WG2 during the three holding times.

\begin{tabular}{ccccc}
\hline \multirow{5}{*}{ WG } & Ranks & & \\
\hline \multirow{5}{*}{ Reflectance } & N & Mean Rank & Sum of Ranks \\
& WG2T20 & 607 & 719.24 & 436.57750 \\
& WG2T40 & 607 & 495.76 & 300.92750 \\
& Total & 1214 & & \\
\cline { 2 - 5 } & WG2T20 & 607 & 902.96 & 548.09850 \\
& WG2T60 & 607 & 312.04 & 189.40650 \\
\cline { 2 - 5 } & Total & 1214 & & \\
\cline { 2 - 5 } & WG2T40 & 607 & 889.15 & 539.71450 \\
& WG2T60 & 607 & 325.85 & \\
& Total & 1214 & & \\
\hline
\end{tabular}


Table A18. Tests statistics table of Mann-Whitney U test for specular solar reflectance of WG2 during the three holding times.

\begin{tabular}{cccc}
\hline \multicolumn{3}{c}{ Test Statistics } \\
\hline \multicolumn{3}{c}{ Reflectance } \\
\hline WG2T20_WG2T40 & WG2T20_WG2T60 & WG2T40_WG2T60 \\
\hline Mann-Whitney U & 116.399500 & 4878.500 & 13.262500 \\
\hline Wilcoxon W & 300.927500 & 189.406500 & 197.790500 \\
\hline Z & -11.107 & -29.367 & -27.995 \\
\hline Asymp. Sig. (2-tailed) & 0.000 & 0.000 & 0.000 \\
\hline
\end{tabular}

Table A19. Ranks table of Mann-Whitney U test for specular solar reflectance of WG3 during the three holding time.

\begin{tabular}{ccccc}
\hline \multirow{5}{*}{ WG } & Ranks & & \\
\hline \multirow{5}{*}{ Reflectance } & N & Mean Rank & Sum of Ranks \\
& WG3T20 & 607 & 308.28 & 187.12700 \\
& WG3T40 & 607 & 906.72 & 550.37800 \\
& Total & 1214 & & \\
\cline { 2 - 5 } & WG3T20 & 607 & 335.00 & 203.34500 \\
& WG3T60 & 607 & 880.00 & 534.16000 \\
\cline { 2 - 5 } & Total & 1214 & & \\
\cline { 2 - 5 } & WG3T40 & 607 & 911.00 & 552.97700 \\
& WG3T60 & 607 & 304.00 & \\
& Total & 1214 & &
\end{tabular}

Table A20. Test statistics table of Mann-Whitney U test for specular solar reflectance of WG3 during the three holding time.

\begin{tabular}{cccc}
\hline \multicolumn{3}{c}{ Test Statistics } \\
\hline & Reflectance \\
\hline WG3T20_WG3T40 & WG3T20_WG3T60 & WG3T40_WG3T60 \\
\hline Mann-Whitney U & 2599.000 & 18.817000 & 0.000 \\
\hline Wilcoxon W & 187.127000 & 203.345000 & 184.528000 \\
\hline Z & -29.747 & -28.977 & -32.251 \\
\hline Asymp. Sig. (2-tailed) & 0.000 & 0.000 & 0.000 \\
\hline
\end{tabular}

\section{References}

1. Blengini, G.A.; Busto, M.; Fantoni, M.; Fino, D. Eco-efficient waste glass recycling: Integrated waste management and green product development through LCA. Waste Manag. 2012, 32, 1000-1008. [CrossRef] [PubMed]

2. Allevi, E.; Gnudi, A.; Konnov, I.V.; Oggioni, G. Municipal solid waste management in circular economy: A sequential optimization model. Energy Econ. 2021, 100, 105383. [CrossRef]

3. Shao, Y.; Lefort, T.; Moras, S.; Rodriguez, D. Studies on concrete containing ground waste glass. Cem. Concr. Res. 2000, 30, 91-100. [CrossRef]

4. Conte, S.; Zanelli, C.; Molinari, C.; Guarini, G.; Dondi, M. Glassy wastes as feldspar substitutes in porcelain stoneware tiles: Thermal behaviour and effect on sintering process. Mater. Chem. Phys. 2020, 256, 123613. [CrossRef]

5. Demir, I. Reuse of waste glass in building brick production. Waste Manag. Res. 2009, 27, 572-577. [CrossRef]

6. Lassinantti Gualtieri, M.; Mugoni, C.; Guandalini, S.; Cattini, A.; Mazzini, D.; Alboni, C.; Siligardi, C. Glass recycling in the production of low-temperature stoneware tiles. J. Clean. Prod. 2018, 197, 1531-1539. [CrossRef]

7. Phonphuak, N.; Kanyakam, S.; Chindaprasirt, P. Utilization of waste glass to enhance physical-mechanical properties of fired clay brick. J. Clean. Prod. 2016, 112, 3057-3062. [CrossRef]

8. Abdeen, H.; Shihada, S. Properties of Fired Clay Bricks Mixed with Waste Glass. J. Sci. Res. Rep. 2017, 13, 1-9. [CrossRef] 
9. Silva, R.V.; de Brito, J.; Lye, C.Q.; Dhir, R.K. The role of glass waste in the production of ceramic-based products and other applications: A review. J. Clean. Prod. 2017, 167, 346-364. [CrossRef]

10. Kalirajan, M.; Ranjeeth, R.; Vinothan, R.; Vidyavathy, S.M.; Srinivasan, N.R. Influence of glass wastes on the microstructural evolution and crystallization kinetics of glass-ceramic glaze. Ceram. Int. 2016, 42, 18724-18731. [CrossRef]

11. Dal Bó, M.; Bernardin, A.M.; Hotza, D. Formulation of ceramic engobes with recycled glass using mixture design. J. Clean. Prod. 2014, 69, 243-249. [CrossRef]

12. Anggono, A.D.; Lopo, E.B.; Sedyono, J.; Riyadi, T.W.B. Fabrication of glaze material from recycled bottle glass and kaolin. Adv. Sci. Technol. Eng. Syst. 2019, 4, 313-320. [CrossRef]

13. de Souza-Dal Bó, G.C.; Bó, M.D.; Bernardin, A.M. Reuse of laminated glass waste in the manufacture of ceramic frits and glazes. Mater. Chem. Phys. 2021, 257, 123847. [CrossRef]

14. Gol, F.; Yilmaz, A.; Kacar, E.; Simsek, S.; Sarıtas, Z.G.; Ture, C.; Arslan, M.; Bekmezci, M.; Burhan, H.; Sen, F. Reuse of glass waste in the manufacture of ceramic tableware glazes. Ceram. Int. 2021, 47, 21031-21068. [CrossRef]

15. Zimmer, A.; Bragança, S.R. A review of waste glass as a raw material for whitewares. J. Environ. Manag. 2019, $244,161-171$. [CrossRef]

16. Kurtulus, R.; Kavas, T. Investigation on the physical properties, shielding parameters, glass formation ability, and cost analysis for waste soda-lime-silica (SLS) glass containing SrO. Radiat. Phys. Chem. 2020, 176, 109090. [CrossRef]

17. Kurtulus, R.; Kavas, T.; Akkurt, I.; Gunoglu, K. An experimental study and WinXCom calculations on X-ray photon characteristics of Bi2O3- and Sb2O3-added waste soda-lime-silica glass. Ceram. Int. 2020, 46, 21120-21127. [CrossRef]

18. Kurtulus, R.; Kavas, T.; Akkurt, I.; Gunoglu, K. Theoretical and experimental gamma-rays attenuation characteristics of waste soda-lime glass doped with La2O3 and Gd2O3. Ceram. Int. 2021, 47, 8424-8432. [CrossRef]

19. Kurtulus, R.; Kavas, T.; Mahmoud, K.A.; Akkurt, I.; Gunoglu, K.; Sayyed, M.I. Evaluation of gamma-rays attenuation competences for waste soda-lime glass containing MoO3: Experimental study, XCOM computations, and MCNP-5 results. J. Non-Cryst. Solids. 2021, 557, 120572. [CrossRef]

20. Hu, B.; Hui, W. Lead recovery from waste CRT funnel glass by high-temperature melting process. J. Hazard. Mater. 2018, 343, 220-226. [CrossRef]

21. Lv, J.; Yang, H.; Jin, Z.; Ma, Z.; Song, Y. Feasibility of lead extraction from waste Cathode-Ray-Tubes (CRT) funnel glass through a lead smelting process. Waste Manag. 2016, 57, 198-206. [CrossRef] [PubMed]

22. Meng, W.; Wang, X.; Yuan, W.; Wang, J.; Song, G. The Recycling of Leaded Glass in Cathode Ray Tube (CRT). Procedia Environ. Sci. 2016, 31, 954-960. [CrossRef]

23. Singh, N.; Wang, J.; Li, J. Waste Cathode Rays Tube: An Assessment of Global Demand for Processing. Procedia Environ. Sci. 2016, 31, 465-474. [CrossRef]

24. Westland, S. CIE Whiteness. In Encyclopedia of Color Science and Technology; Luo, R., Ed.; Springer: Berlin/Heidelberg, Geramny, 2015. [CrossRef]

25. Samoilenko, N.; Shchukina, L.; Baranova, A. Development of engobe composition with the use of pharmaceutical glass waste for glazed ceramic granite. East. Eur. J. Enterp. Technol. 2021, 4, 6-12. [CrossRef]

26. Bloomfield, L. How Things Work: The Physics of Everyday Life, 2nd ed.; Wiley: New York, NY, USA, 2001. 